\title{
ANALYSIS OF IMPLEMENTATION CONTINUUM OF CARE PROGRAM TO CHILD UNDER 5 YEARS
}

\author{
Evi Hasnita ${ }^{1}$ Nurhayati $^{2}$ dan Novi Zetri Utami ${ }^{3}$ \\ STIKes Fort De Kock Bukittinggi \\ novizetriutami@yahoo.com
}

Submitted: 29-11-2017, Reviewer: 15-01-2018, Accepted: 17-10-2018

\begin{abstract}
ABSTRAK
Kematian anak dibawah 5 tahun disebabkan oleh pneumonia, diare, malaria, komplikasi penyakit, kelahiran prematur, lahir asfiksia, sepsis, cedera, kelainan kongenital, dan gangguan gizi. Untuk menurunkan angka kematian tersebut, WHO dan organisasi dunia lainnya menganjurkan untuk Continuum Of Care.Penelitian ini bertujuan untuk menganalisis program Continuum Of Care pada pelayanan kesehatan bayi dan balita di puskesmas Kota Bukittinggi tahun 2016. Metode penelitian kualitatif, dengan pendekatan fenomenologi. Penelitian dilakukan di wilayah kerja dinas kesehatan Kota Bukittinggi, bulan SeptemberOktober 2017. Informan terdiri dari Kepala Dinas Kesehatan, Pemegang program KIA di Dinas Kesehatan, Kepala Puskesmas, Pemegang Program Anak di Puskesmas, dan Bidan Praktek Mandiri. Pemilihan informan secara purposive sampling. Pengumpulan data dilakukan melalui wawancara mendalam dan diolah serta dianalisis secara kualitatif. Hasil penelitian diketahui input seperti kebijakan mengacu pada visi misi Walikota, jumlah tenaga belum mencukupi, ketersediaan dana cukup, dan ketersediaan sarana prasarana cukup. Proses Pelaksanaan program perlu ditingkatkan. Dan Output yang diperoleh, program Continuum Of Care di Puskesmas Kota Bukittinggi belum tercapai, karna sasaran terlalu tinggi dan masih kurangnya partisipasi masyarakat untuk berkunjung ke fasilitas kesehatan serta perlu ditingkatkan lagi kerja sama dengan lintas sektor. Disimpulkan bahwa program Continuum Of Care di Puskesmas Kota Bukittinggi belum mencapai Standar Pelayanan Minimum dan diharapkan dapat meningkatkan pelayanan yang lebih baik lagi.
\end{abstract}

Kata kunci: Continuum Of Care, Kesehatan bayi, Kesehatan balita

\section{ABSTRACT}

Deaths of children under 5 years are caused by pneumonia, diarrhea, malaria, disease complications, premature, asphyxia, sepsis, accident, congenital abnormalities, and nutritional disorders. To reduce the number of such deaths, the WHO and other world organizations advocating for Continuum of Care.This research purpose to analys Continuum Of Careprogram to infants and child under 5 years health service in the primary health center Bukittinggi City 2016. The research by methods qualitative research, with a phenomenological approach. The study was conducted in the working area of the health department of Bukittinggi city, in September-October 2017. The informant are head of the Health Office, Mother and Child Health Program holder in Health Office, head of the primary health center, Child helath program holder in the primary health center, and private practice midwife. Informants election by purposive sampling. Data collection was conducted through interviews and processed and analyzed qualitatively. The results are known inputs such as policy refers to the vision and mission of the mayor, the amount of power is not sufficient, the availability of sufficient funds, the availability of sufficient infrastructure. Proces is implementation of the program should be increased. And output obtained, the Continuum Of Care program in the primary health center Bukittinggi 2016 has not been achieved, because the target is too high and the lack of participation of the community to visit health facilities as well as enhanced cooperation with the relevant sectors. It was concluded that Continuum Of Care program the primary health center has not reached Minimum Service Standard Bukittinggi City and is expected to improve the service even better. 
Keywords: Continuum Of Care, Infant health, child under 5 years health

\section{PENDAHULUAN}

Perawatan kesehatan ibu, bayi dan anak yang buruk tetap menjadimasalah yang signifikan di negara berpenghasilan rendah dan menengah atau Low and Middle Income Countries(LMICs).Mayoritas kematian ibu terjadiselama atau segera setelah melahirkan. Sedangkan risiko kematian seoranganak paling tinggi terjadi selama 28 hari pertama kehidupan. Anak-anak diLMIC hampir 56 kali lebih mungkin meninggal sebelum usia lima tahundibandingkan anak-anak di negara berpenghasilan tinggi atau High IncomeCountries(HIC). (Zohra, et al. 2014)

Angka kematian neonatal di seluruh dunia turun dari 23 kematian per1.000 kelahiran hidup pada tahun 2010 menjadi 19 kematian per 1.000 kelahiran hidup pada tahun 2015. Sedangkan angka kematian balita turun dari52 kematian per 1.000 kelahiran hidup pada tahun 2010 menjadi sekitar 43kematian per 1.000 kelahiran hidup pada tahun 2015. Jumlah dari kematian balita di seluruh dunia telah menurun dari 7, 013 juta di tahun 2010 menjadi 5,9 juta pada tahun 2015 yang artinya 16.000 kematian setiap haridibandingkan dengan 19.000 pada tahun 2010. (UNICEF.2015)

Bukti dan masalah menarik perhatian untuk merumuskan kebijakan dan adopsi, bahwa advokasi dan kepemimpinan bersama komitmen negaradan pemograman dana berjalan secara domestik, sehingga mengakibatkanpeningkatan cakupan intervensi dan akhirnya mengurangi angka kematianneonatal. (Darmstadt GL, et al. 2014)

Pada tahun 2013, dari 6,3 juta anak lahir hidup di seluruh dunia meninggal sebelum usia 5 tahun. Dimana 51,8\% (3,257 juta) meninggal karena penyebab infeksi. $44 \%$ (2,761 juta) meninggal dalam periode neonatal. Kematian anak disebabkan oleh pneumonia, diare, malaria, komplikasi kelahiran prematur, lahir asfiksia, sepsis, cedera, kelainan kongenital. (Li liu, et al. 2015). Meskipun kemajuan telah dibuat di banyak negara, laju peningkatan di seluruh dunia masih belum cukup untuk mencapai target MDGs 4, dan di berbagai negara kemajuan tetap lambat atau tidak ada. (Zulfiqar A Bhutta, et al. 2010)

Di wilayah Palestina, tingkat kematian untuk 2002 - 2006 adalah 27,6 kematian per 1.000 kelahiran hidup untuk bayi dan 31,6 kematian per 1.000 kelahiran hidup untuk anak-anak kurang dari 5 tahun. (Abdul Rahim, et al. 2009).

Penelitian Mary $\mathrm{V}$, et all tahun 2010, hampir 4,7 juta ibu, bayi baru lahir, dan anak-anak meninggal setiap tahun di sub-Sahara Afrika. (Mary V, et al. 2010). Sedangkan pada tahun yang sama Cambodia Demographic and Helath Surveys (CDHS) menunjukkan bahwa tingkat kematian balita telah menurun secara dramatis, dari 124 kematian per 1.000 kelahiran hidup pada tahun 2000 menjadi 54 per 1.000 kelahiran hidup pada tahun 2010. (Wang dan Hong. 2015).

Hal ini dapat diberikan sebagai paket utama dari program KIA, dan dapat menunjukkan jalur untuk membantu mengurangi beban dan kematian ibu dan bayi. (Kikuchi K et al. 2015)

Continuum of careatau CoCmemperhatikan kualitas asuhan dari waktu ke waktu. Ini adalah proses di mana pasien dan tenaga kesehatan terlibat secara kooperatif dalam perawatan kesehatan berkelanjutan untuk tujuan bersama, yaitu perawatan kesehatan berkualitas tinggi dan hemat biaya. (AAFP. 2015) 


\section{Continuum of care untuk kesehatan} ibu, bayi dan anak membutuhkan akses ke perawatan yang diberikan oleh keluarga dan masyarakat, oleh layanan rawat jalan atau outreach, dan layanan klinis di seluruh siklus hidup, termasuk masa kanak-kanak, remaja, kehamilan, melahirkan, dan periode postnatal. (Kate J Kerber, et al. 2007) yang merupakan suatu langkah penting menuju masa kecil yang sehat dan kehidupan yang produktif. (Tinker A, 2005). Selain itu untuk dimensi ruang continuum of care, komponen dasar dari intervensi adalah hubungan antara perawatan keluarga, masyarakat, rawat jalan, dan perawatan klinis. (Kikuchi K et al. 2015).

Di Ghana, hanya $8,0 \%$ yang menyelesaikan $\mathrm{CoC}$, kesenjangan terbesar dan kontributor $\mathrm{CoC}$ rendah terdeteksi antara persalinan dan perawatan setelah melahirkan dalam waktu 48 jam setelah melahirkan. Sekitar 95\% dari wanita memiliki minimal 4 kunjungan antenatal dan postnatal di 6 minggu setelah melahirkan. Sebanyak 75\% tenaga terampil dan $25 \%$ ibu menerima perawatan setelah melahirkan dalam waktu 48 jam. Faktor yang terkait dengan $\mathrm{CoC}$ adalah lokasi geografis, status perkawinan, pendidikan, transportasi dan keyakinan tentang penyakit anak. (Yeji F, et al. 2015).

Pada tahun 2014, The Stillbirth And Neonatal Death Study (SANDS) mengatakan $40 \%$ kematian neonatal terjadi pada hari pertama setelah kelahiran, dan penyebab utama kematian neonatal dini adalah asfiksia dan prematuritas. Selain itu kematian bayi juga dipengaruhi oleh hambatan sosial dan budaya yang signifikan. (Cyril, et al. 2016)

Di Pakistan intervensi perawatan bayi baru lahir yang disampaikan melalui petugas kesehatan outreach dikaitkan dengan penurunan angka kematian perinatal dan neonatal di daerah intervensi. (Memon, et al. 2015). Sedangkan di Uttar Pradesh, ada sedikit perubahan, dibandingkan dengan daerah kontrol, angka kematian neonatal berkurang 54\% dalam daerah intervensi perawatan baru lahir dan $52 \%$ pada daerah perawatan essential. (Kumar V, et al. 2008).

Keberhasilan pelaksanaan program untuk meningkatkan continuum of care bergantung pada pemahaman yang lebih baik dari di mana kesenjangan dalam mencari perawatan sepanjang jalur dan faktor-faktor apa yang berkontribusi terhadap kesenjangannya. (Wang dan Hong. 2015).

Dengan banyaknya program dimana daerah fokus tumpang tindih, campuran keterampilan untuk menyampaikan berbagai intervensi $\mathrm{MNCH}$ tidak ada. Komunitas kader petugas kesehatan, petugas kesehatan desa dilatih dalam vaksinasi dan melakukan klinik vaksinasi outreach sementara pekerja perawatan kesehatan ibu dilatih dalam perawatan antenatal, imunisasi tetanus, keluarga berencana, perawatan setelah melahirkan dan perawatan kesehatan primer pada ibu. Akibatnya, perawatan terfragmentasi dari klinik penjangkauan mempengaruhi continuum of care yang efektif. (Kc A, Bhandari A, et al. 2011). Sebuah kontinum efektif, bangunan atas interaksi alami terjadi di seluruh siklus hidup. (Joseph de Graft-Johnson, et al).

Di Indonesia berdasarkan hasil SUPAS tahun 2015 AKB sebesar 22,23 per 1.000 kelahiran hidup, yang artinya sudah mencapai target MDGs 2015 sebesar 23 per 1.000 kelahiran hidup. Begitu pula dengan Angka Kematian Balita (AKABA) sebesar 26,29 per 1.000 kelahiran hidup, juga sudah memenuhi target MDGs 2015 sebesar 32 per 1.000 kelahiran hidup. (Dinkes Indonesia 2015) 
Namun demikian, AKB di Indonesia masih termasuk tinggi dibandingkan dengan negara tetangga seperti Malaysia dan Singapura yang sudah di bawah 10 kematian per 1.000 kelahiran bayi. Kematian bayi merupakan salah satu indikator sensitif untuk mengetahui derajat kesehatan suatu negara dan bahkan untuk mengukur tingkat kemajuan suatu bangsa. Tingginya kematian bayi pada usia hingga satu tahun menunjukkan masih rendahnya kualitas sektor kesehatan di negara tersebut. (Sibarani. 2016)

Menurut laporan bertajuk "Promise Renewed: 2015 Progress Report" menyatakan bahwa jumlah kematian balita di Indonesia saat ini adalah 27 kematian per 1.000 kelahiran yang merupakan penurunan signifikan dibandingkan dengan 84 kematian per 1.000 kelahiran pada 1990. Laporan ini memasukkan Indonesia dalam 24 dari 81 negara berpendapatan rendah dan menengah yang berhasil menurunkan angka kematian anak berusia dibawah lima tahun hingga duapertiganya. (Menkes. 2016)

Berdasarkan data Proyeksi Penduduk Indonesia, selama lima tahun terakhir (2012-2016), angka kematian bayi secara nasional selalu mengalami penurunan. Pada tahun 2012 angka kematian bayi tercatat sebesar 28 per1.000 kelahiran hidup. Pada tahun 2016, angka tersebut turun menjadi sekitar 26 kematian bayi dalam 1.000 kelahiran hidup. Provinsi dengan estimasi angka kematian bayi paling rendah pada tahun 2016 adalah DI Yogyakarta yaitu sekitar 13 kematian bayi dalam 1.000 kelahiran hidup. Sedangkan estimasi AKB tertinggi terdapat di Provinsi Sulawesi Barat yaitu sebesar 50 kematian bayi dalam 1.000 kelahiran hidup. Dan estimasi AKB di Provinsi Sumatera Barat yaitu sebesar 30 kematian bayi dalam 1.000 kelahiran hidup. (Menkes. 2016)
Di Kota Bukittinggi Angka

Kematian Bayi (AKB) tahun 2015 sebesar 11 kematian bayi dalam 1.000 kelahiran hidup. Angka ini mengalami peningkatan yang pesat dibandingkan tahun 2014 lalu yang sebesar 8 kematian bayi dalam 1.000 kelahiran hidup. (Dinkes Kota Bukittinggi, 2015).

Fenomena jumlah kematian bayi di kota Bukittinggi mengalami naik turun. Penyebab kematian tertinggi pada tahun 2015 di kota Bukittinggi untuk neonatus adalah Asfiksia dan Prematur, sedangkan pada tahun 2016 yaitu BBLR dan Asfiksia. (Dinkes Kota Bukittinggi, 2016).

Untuk meningkatkan kesehatan ibu dan menurunkan angka kematian bayi, salah satunya adalah intervensi dengan pendekatan continuum of care. Continuum of care atau asuhan berkesinambungan adalah asuhan yang disediakan secara komprehensif disepanjang siklus hidup perempuan serta diberikan dalam tempat yang berkesinambungan mencakup rumah, komunitas, puskesmas, dan tempat rujukan. Continuum of care merupakan intervensi yang terbukti dapat menurunkan kematian ibu dan bayi. (Kate J Kerber, et al. 2007).

Continuum of care fokus pada kehamilan, persalinan dan pascapersalinan untuk mencegah kematian ibu dan bayi baru lahir. Tujuannya adalah untuk memberikan perawatan kesehatan reproduksi wanita yang mereka butuhkan sebelum, selama, setelah kehamilan dan persalinan serta untuk memungkinkan bayi yang baru lahir tumbuh menjadi anak-anak yang sehat. Penekanan ditempatkan pada pendekatan terintegrasi terpadu untuk ibu dan bayi baru lahir dan peran fasilitas perawatan dasar, rawat jalan dan perawatan berbasis masyarakat atau 
perawatan di rumah selama siklus hidup. (Singh K, et al. 2016)

Menurut hasil penelitian Marliana dan Reni yang berjudul Continuum of Care Improve Maternal And Neonatal Health In the District Subang Tahun 2016, masalah terberat ada pada siklus remaja. Klasifikasi masalah berdasarkan siklus continuum of care adalah sebagai berikut : Masa remaja dan sebelum kehamilan $(20.8 \%)$, bayi baru lahir $(8.9 \%)$, kehamilan $(8.4 \%)$, nifas $(5.8 \%)$, persalinan (5.0\%). (Marliana dan Reni. 2016).

Penelitian ini bertujuan untuk melakukan pengkajian terhadap masalah kesehatan ibu dan bayi di Kota Bukittinggi dengan pelaksanaan program continuum of care khususnya pada bayi dan balita di seluruh puskesmas kota Bukittinggi sehingga dapat menurunkan angka kematian bayi dan balita di Kota Bukittinggi.

\section{METODE PENELITIAN}

Penelitian ini merupakan penelitian kualitatif dengan pendekatan fenomenologi. Dilakukan di seluruh Puskesmas Kota Bukittinggi. Pemilihan informan dalam penelitian ini adalah secara Purposive Sampling.

\section{HASIL DAN PEMBAHASAN}

\section{A. INPUT}

\section{Kebijakan}

\begin{tabular}{|c|c|c|c|}
\hline $\begin{array}{l}\text { Doku } \\
\text {-men }\end{array}$ & $\begin{array}{l}\text { Obser } \\
\text { vasi }\end{array}$ & Wawancara & $\begin{array}{l}\text { Analisis } \\
\text { Triangulasi }\end{array}$ \\
\hline $\begin{array}{l}\text { Ada } \\
\text { buku } \\
\text { Pedo } \\
\text { man } \\
\text { pelay } \\
\text { anan } \\
\text { keseh } \\
\text { atan } \\
\text { bayi } \\
\text { dan } \\
\text { balita } \\
\text { dari } \\
\text { pemer } \\
\text { intah }\end{array}$ & $\begin{array}{l}\text { Pemeg } \\
\text { ang } \\
\text { Progra } \\
\mathrm{m} \\
\text { dalam } \\
\text { melak } \\
\text { sanaka } \\
\mathrm{n} \\
\text { kegiat } \\
\text { an } \\
\text { progra } \\
\mathrm{m} \\
\text { contin } \\
\text { uum } \\
\text { of } \\
\text { care } \\
\text { berdas }\end{array}$ & $\begin{array}{l}\text { Kebijakan } \\
\text { pada } \\
\text { pelayanan } \\
\text { kesehatan bayi } \\
\text { dan balita } \\
\text { mengacu } \\
\text { kepada visi } \\
\text { dan misi kota } \\
\text { Bukittinggi, } \\
\text { RPJMD, } \\
\text { RENSTRA, } \\
\text { RENJA, } \\
\text { sesuai dengan } \\
\text { peraturan yang } \\
\text { telah ada baik } \\
\text { itu dari pusat, } \\
\text { pemda, }\end{array}$ & $\begin{array}{l}\text { Kebijakan pada } \\
\text { pelayanan kesehatan } \\
\text { bayi dan balita } \\
\text { selama ini mengacu } \\
\text { kepada visi dan misi } \\
\text { kota Bukittinggi, } \\
\text { RPJMD, } \\
\text { RENSTRA, RENJA, } \\
\text { sesuai dengan } \\
\text { peraturan yang telah } \\
\text { ada baik itu dari } \\
\text { pusat, pemda, } \\
\text { maupun yang telah } \\
\text { di SK kan oleh } \\
\text { Kepala Puskesmas. } \\
\text { Baik itu berupa buku } \\
\text { pedoman dan buku }\end{array}$ \\
\hline
\end{tabular}

\begin{tabular}{lll}
\hline arkan & maupun yang & petunjuk teknis \\
buku & telah di SK & program continuum \\
pedom & kan oleh & of care pada bayi \\
an & Kepala & dan balita yang \\
yang & Puskesmas. & dikeluarkan \\
sudah & & Kementerian \\
ada & & Kesehatan RI \\
\hline
\end{tabular}

Berdasarkan hasil wawancara dapat disimpulkan bahwa kebijakan tentang pelaksanaan pelayanan kesehatan bayi dan balita di Puskesmas Kota Bukittinggi pada prinsipnya mengacu pada visi dan misi walikota Kota Bukittinggi. RPJMD RENSTRA (Rencana Strategis), RENJA (Rencana Kerja), dan sesuai dengan peraturan pemerintah yang sudah ada baik itu dari pusat, pemda, dinas kesehatan, maupun yang telah di SK kan oleh kepala puskesmas, serta sesuai dengan SOP (Standar Operasional Prosedur).

Penelitian ini sejalan dengan penelitian Pranata dkk bahwa upaya kesehatan yang dilakukan untuk menurunkan AKB dan AKI, oleh Soemantri (2004) dinilai mempunyai ketergantungan pada efisiensi input yang berupa sumber daya manusia, sarana dan dana. Disisi lain, upaya kesehatan tersebut juga tidak dapat lepas dari pengaruh kebijakan, manajemen kesehatan dan pemberdayaan masyarakat.

Penelitian ini tidak sejalan dengan penelitian Candra dkk tahun 2011 dimana faktor pendorong yang berhubungan dengan pelayanan KIA antara lain belum ada kebijakan daerah sebagai acuan, dana pendukung pelayanan belum memadai serta kuantitas kegiatan yang seharusnya dilakukan secara lintas sektoral masih banyak yang belum terealisasi dan belum optimal.

Berdasarkan penelitian Halwatiah yang berjudul implementasi kebijakan pelayanan kesehatan ibu dan anak di kabupaten takalar provinsi sulawesi selatan, bahwa kebijakan KBD (kemitraan bidan dan dukun) dilihat pada sisi kebijakan merupakan solusi 
kreatif berbasis kearifan lokal karena fakta lapangan masyarakat masih mempercayai peran dukun, penggunaan data pasien sudah cukup dimaksimalkan, kebijakan monitoring dan evaluasi program juga berjalan dengan baik, dalam sisi komunikasi juga sudah baik, adanya pertemuan rutin agen pelaksana, pelatihan yang telah dilakukan sehingga agen pelaksana sudah mengetahui persis apa yang harus dilakukan. Dan model implementasi kebijakan pelayanan lokal harus memiliki payung hukum kebijakan nasional.

Menurut asumsi peneliti, analisis kebijakan pelaksanaan program continuum of care pada pelayanan kesehatan bayi dan balita di Puskesmas Kota Bukittinggi pada prinsipnya telah mengacu kepada visi dan misi Kota Bukittinggi. Jika telah ada kebijakan suatu daerah sebagai acuan, maka program dari pemerintah dapat berjalan maksimal seperti yang harapkan. Kebijakan dinas kesehatan menjadikan program KIA ini sebagai programprioritas menyebabkan puskesmas juga harus menjadikan program tersebut sebagai program prioritas. Hal tersebut dikarenakan dinas kesehatan berfungsi sebagai pendukung kegiatan puskesmas diwilayah kerjanya sedangkan penetapannya dilakukan oleh peraturan daerah. Dan kebijakan umum pembangunan kesehatan nasional, upaya penurunan angka kematian bayi dan balita merupakan bagian penting dalam Program Nasional Bagi Anak Indonesia (PNBAI).

\section{Sumber Daya Manusia}

\begin{tabular}{lll}
\hline Observasi & Wawancara & $\begin{array}{l}\text { Analisis } \\
\text { Triangulasi }\end{array}$ \\
\hline Tenaga & Tenaga & Tenaga \\
pelaksanaan & pelaksana dalam & dalam \\
pelayanan & program & program \\
kesehatan bayi & continuum of & continuum of \\
dan balita & care pada & care pada \\
merangkap, & pelayanan & pelayanan \\
Saat melakukan & kesehatan bayi & kesehatan \\
pelayanan dalam & dan balitadi & bayi dan \\
\hline
\end{tabular}

\begin{tabular}{lll}
\hline gedung (UKP) & wilayah kerja & balitadi \\
petugas juga & Puskesmas & wilayah \\
turun ke & secara umum & kerja \\
lapangan dan & masih kurang & puskesmas \\
harus & dan belum & masih \\
memberikan & maksimal & kurang. \\
pelayanan & karena masih & \\
(UKM) & adanya rangkap & \\
& jabatan. & \\
\hline
\end{tabular}

Berdasarkan hasil wawancara dapat disimpulkan bahwa ketersediaan tenaga pelaksana pada pelayanan kesehatan bayi dan balita di Puskesmas Kota Bukittinggi masih kurang, dan untuk di tingkat Dinas Kesehatan itu sudah cukup. Rata-rata tenaga pelaksana tersebut berpendidikan D III dan S 1 atau D 4 Kebidanan. Tenaga pelaksana sudah ada yang mengikuti pelatihan.

World Health Organization (2006) melaporkan bahwa tenaga kesehatan memberikan konstribusi hingga 80\% dalam keberhasilan pembangunan kesehatan dan salah satu jalan terbaik untuk menyelesaikan krisis ketenagaan Sumber Daya Manusia (SDM) Kesehatan yaitu melalui pendidikan dan pelatihan, bersama dengan perbaikan kebijakan manajemen SDM. (Efendi dan Kurniati, 2012)

Penelitian ini sejalan dengan penelitian Mujiati dan Yuniar tahun 2016 yang berjudul "Availability of Human Resources for Health in Health Facilities in the Era of National Health Insurance in Eight Districts-Cities in Indonesia" Puskesmas di 8 kabupaten/kota belum seluruhnya memiliki SDM kesehatan sesuai Permenkes RI Nomor 75 tahun 2014, namun dokter umum, bidan dan perawat telah tersedia di seluruh puskesmas meskipun dengan jumlah yang masih kurang. Terdapat perubahan dalam perencanaan pengadaan SDM di daerah sesudah JKN, peningkatan beban kerja dan jam kerja, sehingga diperlukan perencanaan dan pengadaan SDM berbasis kebutuhan.

Menurut hasil penelitian L Paruntu $\mathrm{BR}$, et all tahun 2015 yang berjudul 


\section{"Human Resource Requirements} Planning in Health Center Minahasa District" bahwa menunjukkan pengadaan sumber daya manusia kesehatan baik dinas kesehaatan maupun puskesmas tidak ada kesamaan persepsi tentang metode atau alat ukur. Manajemen puskesmas dan manajemen dinas kesehatan kurang komunikasi dan koordinasi.

Menurut asumsi peneliti, analisis ketersediaan tenaga pelaksana program continuum of care pada pelayanan kesehatan bayi dan balita di Puskesmas Kota Bukittinggi belum mencukupi karna banyaknya kerja petugas yang rangkap yang seharusnya kerja di pelayanan atau di dalam gedung tetapi juga harus turun ke lapangan atau ke luar gedung. Program continuum of care pada pelayanan kesehatan bayi dan balita belum tercapai, karna masih adanya AKB dan AKABA di kota Bukittinggi. Untuk itu perlu adanya komunikasi dan koordinasi yang baik antara puskesmas dan dinas kesehatan.

\section{Dana}

Berdasarkan hasil wawancara disimpulkan bahwa sumber dana pelaksanaan program continuum of care pada pelayanan kesehatan bayi dan balita di dinas kesehatan atau dari puskesmas berasal dari APBN, DEKON, APBD, BOK, JKN, sedangkan untuk program KIA sumber dananya diambil dari DAK non fisik, Ketersediaan dana yang ada sudah mencukupi untuk dinas kesehatan dan puskesmas dan tidak ada kendala.

Dana merupakan penunjang keberhasilan dalam pelaksanaan pelayanan di puskesmas, dengan adanya dana yang mencukupi maka tujuan dari puskesmas menjadikan pelayanan kesehatan yang optimal akan berjalan dengan baik. Adapun pembangunan kesehatan memperoleh perioritas.

Penelitian ini sejalan dengan Aridewi dkk bahwa pada puskesmas dengan serapan tinggi dan berhasil menekan kasus, pemahaman tentang juknis BOK jelas, pelaksanaan kegiatan sesuai dengan laporan dan dilaksanakan secara tim, ada keterlibatan pelaksana dalam penyusunan Plan of Action (POA) serta ada evaluasi pelaksanaan kegiatan. Selain itu pada puskesmas yang berhasil, pelaksana kegiatan juga menyusun kelengkapan data pendukung sehingga pembuatan laporan tidak hanya dibebankan kepada TimPengelola BOK Puskesmas. Demi keberhasilan implementasi kebijakan pemanfaatan BOK untuk peningkatan kesehatan ibu dan anak, perlu penerapan fungsi manajemen yang benar di Puskesmas yang meliputi perencanaan, pelaksanaan, dan evaluasi

Penelitian ini tidak sejalan dengan penelitian Iswarno dkk tahun 2013 bahwa komitmen politik pemerintah daerah terhadap program KIA masih rendah, ini terbukti dengan minimnya alokasi anggaran program KIA.

Keterlibatan stakeholder lokal dalam proses perencanaan dan penganggaran program masih kurang. Koordinasi antara dinas kesehatan dengan stakeholder kunci dalam perencanaan dan penganggaran juga tidak berjalan dengan baik, sehingga sering terjadi perbedaan pemahaman tentang program. Selain itu kualitas perencanaan kegiatan dinilai masih rendah, dan lemahnya advokasi dinas kesehatan.

Menurut asumsi peneliti, ketersediaan dana dalam program continuum of care pada pelayanan kesehatan bayi dan balita sudahmencukupi dari pemerintah dalam bentuk APBD, APBN, DEKON, BPJS, JKN atau BOK. Alokasi dananya tergantung anggarannya, misalkan tahun 2017 ini, berarti udah dianggarkan ditahun 2016. Adanya dana BOK untuk upaya preventif dan promosi. Oleh 
karena itu perlunya advokasi dengan dinas kesehatan.

\section{Sarana dan Prasarana}

\begin{tabular}{lll}
\hline Observasi & Wawancara & Analisis Triangulasi \\
\hline Terdapat & Sarana dan & Sarana dan prasarana \\
beberapa & prasarana & dalam pelaksanaan \\
sarana dan & untuk & pelayanan kesehatan \\
prasarana & pelayanan & bayi dan balita secara \\
puskesmas & kesehatan & keseluruhan sudah \\
yang & bayi dan & memadai dan \\
belum & balita secara & mencukupi walaupun \\
sesuai & keseluruhan & masih ada beberapa \\
peraturan & sudah & sarana dan prasarana \\
pemerinta & memadai & yang belum lengkap \\
h no 75 & dan & sesuai dengan \\
tahun & mencukupi & peraturan pemerintah \\
2014 & & no 75 tahun 2014 \\
tentang & & tentang puskesmas \\
puskesmas & & \\
\hline
\end{tabular}

Berdasarkan hasil wawancara disimpulkan bahwa sarana prasarana program continuum of care pada pelayanan kesehatan bayi dan balita di puskesmas kota Bukittinggi sudah cukup. Tetapi masih ada yang belum mencukupi, masih ada alat yang belum lengkap, ini di tunjang dengan lembar ceklis sarana prasarana sesuai dengan permenkes yang di berikan oleh peneliti, belum sesuai dengan peraturan pemerintah.

Sarana kesehatan adalah segala macam peralatan yang digunakan tenaga medis/para medis untuk memudahkan penyampaian pelayanan kesehatan. Lalu dapat dirumuskan bahwa prasarana kesehatan adalah segala macam peralatan, kelengkapan, dan benda-benda yang digunakan petugas puskesmas untuk memudahkan penyelenggaraan puskesmas. (Hidayat. 2015)

Pemerintah mengeluarkan peraturan untuk sarana dan prasarana untuk pelayanan kesehatan yang terdapat pada Permenkes no 75 tahun 2014, yang mengatur/menentukan standar sarana dan prasarana pelayanan kesehatan, khusus nya pada pelayanan kesehatan ibu dan anak.
Penelitian ini sejalan dengan Marniyati dan kawan-kawan tahun 2016 dimana masih terdapat sarana dan prasarana yang belum memadai untuk melakukan pelayanan sesuai standar.

Menurut asumsi peneliti, analisis ketersediaan sarana prasarana yang mendukung pelaksanaan program continuum of care pada pelayanan kesehatan bayi dan balita, belum mencukupi, ini juga di tunjang dengan penilaian melalui lembar ceklis tentang sarana dan prasarana yang di keluarkan oleh permenkes no 75 tahun 2014, sarana merupakan salah satu faktor yang menunjang tercapainya program continuum of care pada pelayanan kesehatan bayi dan balita, kurangnya sarana prasarana pendukung program ini akan berdampak pada pelaksanaan program tersebut.

Hal ini tentunya akan berdampak pada rendahnya pencapaian program continuum of care pada pelayanan kesehatan bayi dan balita di puskesmas. Dalam menjalankan pelayanan medis puskesmas harus memiliki sarana dan prasarana yang lengkap, guna memaksimalkan pelayanan kepada masyarakat.

\section{B. PROSES}

\section{Pelaksanaan}

\begin{tabular}{|c|c|c|}
\hline Dokumen & Wawancara & $\begin{array}{l}\text { Analisis } \\
\text { Triangulasi }\end{array}$ \\
\hline $\begin{array}{l}\text { Ada } \\
\text { laporan } \\
\text { pelaksanaa } \\
\text { n kegiatan } \\
\text { program } \\
\text { continuum } \\
\text { of care } \\
\text { pada bayi } \\
\text { dan balita }\end{array}$ & $\begin{array}{l}\text { Pelaksanaan } \\
\text { program } \\
\text { continuum of } \\
\text { care pada bayi } \\
\text { dan balita } \\
\text { sudah mengacu } \\
\text { kepada SOP, } \\
\text { melibatkan } \\
\text { lintas program, } \\
\text { lintas sektor } \\
\text { tapi belum } \\
\text { maksimal }\end{array}$ & $\begin{array}{l}\text { Pelaksanaan } \\
\text { program continuum } \\
\text { of care pada bayi } \\
\text { dan balita sudah } \\
\text { mengacu kepada } \\
\text { SOP, melibatkan } \\
\text { lintas program, lintas } \\
\text { sektor tapi belum } \\
\text { maksimal. }\end{array}$ \\
\hline
\end{tabular}

\begin{tabular}{ccr}
\hline Berdasarkan hasil wawancara \\
tersebut dapat disimpulkan
\end{tabular}
bahwapelaksanaan program continuum of care pada pelayanan kesehatan bayi dan balita di puskesmas kota 
Bukittinggi sudah berjalan baik seperti adanya kerja sama antara petugas kesehatan dengan lintas sektor terkait, berjalannya program sesuai dengan jadwal yang telah ditetapkan,tetapi masih terdapat kendala atau masalah seperti sasaran yang terlalu tinggi, kurangnya partisipasi masyarakat membawa anaknya ke posyandu, dan pekerjaan petugas yang rangkap sehingga untuk mencapai SPM (Standar Pelayanan Minimum) agak sedikit sulit.

Pelaksanaan atau penggerakan adalah melakukan kegiatan untukmempengaruhi orang lain agar mau dan suka bekerja dalam rangkamenyelesaikan tugas, demi tercapainya tujuan bersama. Seringkali terjadihambatan pada penggerakan karena yang digerakkan adalah manusia, yangmempunyai keinginan pribadi, sikap dan perilaku yang khusus (Suarli \&Bachtiar 2010)

Hasil penelitian ini sejalan dengan penelitian yang telah dilakukan oleh Basir Hartini (2013) tentang Pelaksanaan Program Pelayanan Kesehatan Gratis Di Kabupaten Wajo diketahu bahwa Tata laksana pelayanan kesehatan gratis sudah terlaksana dengan baik dimana masyarakat mendapatkan pelayanan kesehatan dasar di puskesmas baik itu dalam gedung maupun luar gedung.

Hasil penelitian Saifuddin yang berjudul "Analisis Perencanaan dan Penganggaran Program Kesehatan Ibu danAnak pada Puskesmas di Kota Banjar Tahun 2007" menunjukkan Analisis situasi dan penentuanmasalah sebagian besar informan menyatakan dipengaruhi oleh keadaanmasalah kesehatan, kinerja program, faktor perilaku dan lingkungan. Dalam penentuan tujuan program KIA ada dua fenomena pertama puskesmasmenentukan tujuan sendiri dan kedua puskesmas tidak menentukan tujuantapi mengikuti tujuan dan target dinas. Adapun proses penentuan tujuan/ targetKIA di puskesmas dipengaruhi oleh tujuan dan target dinas, ketersediaananggaran, cakupan target sarana, motivasi pegawai trend kinerja, budaya dantuntutan lingkungan. Keterlibatan lintas program dalam identifikasi kegiatanmuncul dua kelompok pertama perencanaan disusun dengan keterlibatanlintas program kedua perencanaan hanya disusun orang-orang tertentu saja.

Menurut asumsi peneliti, pelaksanaan program continuum of care pada pelayanan kesehatan bayi dan balita di puskesmas Kota Bukittinggi sudah berjalan baik,tetapi masih terdapat kendala atau masalah sehingga untuk mencapai SPM (Standar Pelayanan Minimum) agak sedikit sulit.Kendala dalam pelaksanaan program continuum of care pada pelayanan kesehatan bayi dan balita itu datang dari petugasnya yang pekerjaannya rangkap, pengetahuan petugasnya maupun dari masyarakat nya sendiri seperti yang tidak datang pada saat di lakukan kegiatan, dan kurang nya keinginanmasyarakat untuk memeriksakan kesehatanya ke tenaga kesehatan.

\section{Pengawasan}

\begin{tabular}{|c|c|c|c|}
\hline $\begin{array}{l}\text { Doku } \\
\text { men }\end{array}$ & Observasi & $\begin{array}{l}\text { Wawanca } \\
\text { ra }\end{array}$ & $\begin{array}{l}\text { Analisis } \\
\text { Triangulasi }\end{array}$ \\
\hline $\begin{array}{l}\text { Ada } \\
\text { lapor } \\
\text { an } \\
\text { bulan } \\
\text { an, } \\
\text { lapor } \\
\text { an } \\
\text { tahun } \\
\text { an, } \\
\text { lapor } \\
\text { an } \\
\text { dari } \\
\text { kader }\end{array}$ & $\begin{array}{l}\text { Ada } \\
\text { pertemuan } \\
\text { staf meeting } \\
\text { bulanan } \\
\text { yang di } \\
\text { pimpin } \\
\text { langsung } \\
\text { oleh kepala } \\
\text { puskesmas } \\
\text { membicarak } \\
\text { an semua } \\
\text { permasalaha } \\
\text { n yang } \\
\text { ditemui pada } \\
\text { bulan } \\
\text { sebelumnya. }\end{array}$ & $\begin{array}{l}\text { Pengawas } \\
\text { an dan } \\
\text { evaluasi } \\
\text { dilaksanak } \\
\text { an dalam } \\
\text { waktu } \\
\text { yang } \\
\text { bervariasi } \\
\text { tergantung } \\
\text { dari jenis } \\
\text { kegiatan } \\
\text { ada } \\
\text { perbulan } \\
\text { dan per- } \\
\text { triwulan }\end{array}$ & $\begin{array}{l}\text { Pengawasan } \\
\text { dan evaluasi } \\
\text { dilaksanakan } \\
\text { dalam waktu } \\
\text { yang bervariasi } \\
\text { tergantung dari } \\
\text { jenis } \\
\text { kegiatannya } \\
\text { ada perbulan } \\
\text { dan } \\
\text { pertriwulan. } \\
\text { Dan adanya } \\
\text { pengawasan } \\
\text { dari kapus } \\
\text { maupun dari } \\
\text { dinkes }\end{array}$ \\
\hline & acarlan & & awancara \\
\hline
\end{tabular}


pimpinan puskesmas atau oleh dinas kesehatan dan evaluasinya dengan membuat laporan bulanan.

Pengawasan adalah suatu proses untuk mengetahui apakah pelaksanaan kegiatan/pekerjaan sesuai dengan rencana, pedoman, ketentuan, kebijakan, tujuan dan sasaran yang sudah ditentukan sebelumnya. Maksud dan tujuan pengawasan adalah untuk mencegah atau memperbaiki kesalahan, penyimpangan, dan ketidak sesuaian yang dapat mengakibatkan tujuan organisasi tidak tercapai (Suarli \& Bachtiar 2010).

Hasil penelitian ini sejalan dengan penelitian Kareth, dkk bahwa Supervisi Kepala Puskesmas yang pencatatan \& pelaporan KIAnya baik dilakukan sebulan sekali dan yang kurang baik 3 bulan sekali. Supervisi DKK ke puskesmas yang baik 3 bulan sekali dan puskesmas yang kurang baik 6 bulan sekali.

Menurut asumsi peneliti, sistem pengawasan dilakukan oleh dinas kesehatan Kota Bukittinggi, sangat baik untuk memantau dan mengawasi setiap program kerja, sehingga setiap masalah dan kendala yang ada pada setiap tingkatannya dapat diketahui dandicarikan jalan keluarnya. Suatu pengawasan dikatakan penting karena tanpa adanya pengawasan yang baik tentunya akan menghasilkantujuan yang kurang memuaskan, baik bagi organisasinya itu sendiri maupunbagi para pekerjanya. Di dalam suatu organisasi terdapat tipe-tipepengawasan yang digunakan, seperti pengawasan pendahuluan (input), pengawasan pada saat kerja berlangsung (proses), pengawasan keluaran (output). Di dalam proses pengawasan juga diperlukan tahap-tahap pengawasan untuk mencapai tujuan yang diinginkan. Sistem pengawasan seperti ini juga akan sangat bermanfaat dalam penyusunan rencana kerjaberikutnya, karena bisa mempertimbangkan masalah yang ditemukandilapangan, baik masalah pada pelaksanaan oleh kader, poskeskel maupun masalah yang ada di puskesmas.

\section{OUTPUT}

\begin{tabular}{lll}
\hline Dokumen & Wawancara & Analisis Triangulasi \\
\hline Laporan & Pelaksanaan & Pelaksanaan program \\
tahuan & program & belum bisa maksimal \\
menunjuk & belum bisa & sehingga hasil juga \\
an angka & maksimal & belum sesuai dengan \\
pencapaia & sehingga hasil & target yang \\
n program & juga belum & diharapkan. Masih \\
continuum & sesuai dengan & banyaknya program \\
of care & target yang & continuum of care \\
pada & diharapkan. & pada bayi dan balita \\
bayi, & & yang belum mencapai \\
balita & & target yang telah \\
& & ditetapkan oleh \\
& & pemerintah \\
\hline
\end{tabular}

Berdasarkan hasil wawancara disimpulkan bahwa pencapaian cakupan pelayanan kesehatan pada bayi dan balita atau pencapaian progran continuum of care pada pelayanan kesehatan bayi dan balita masih belum tercapai, karna masih adanya kematian neonatal seperti IUFD, kematian bayi dengan BBLR dan asfiksia, dan kematian balita dengan penyakit penyerta. Maka dari itu programprogram pada pelayanan kesehatan bayi dan balita belum memenuhi SPM yang telah ditetapkan oleh pemerintah seperti DDTK pada balita tidak tercapai. Itu semua dipengaruhi oleh sosial budaya masyarakat seperti tidak ada kunjungan ANC, tidak datang pada saat posyandu, terlalu sibuk karna bekerja, dan lain sebagainya. Kemudian juga dipengaruhi oleh petugas yang pekerjaannya rangkap dan angka yang ditargetkan terlalu tinggi sehingga tidak ditemukan sasarannya. Untuk program DDTK anak sebaiknya Dinas Kesehatan, Dinas Pendidikan, dan Tim Penggerak PKK serta orang tua murid bekerja sama agar program continuum of care pada anak bisa berjalan dengan baik.

Dalam ranah pelayanan kesehatan, ekuitas merupakan keadilan dalam pemberian pelayanan kesehatan kepada 
dua atau lebih kelompok. Salah satu aspek yang berpengaruh dalam ekuitas pelayanan kesehatan adalah akses terhadap pelayanan kesehatan, yang meliputi keberadaan pelayanan kesehatan, akses geografis, ekonomi, dan sosial. (Sari. 2013)

Keberhasilan suatu program kesehatan, khususnya program kesehatan masyarakat antara lain tergantung pada komunikasi informasi yang akurat dan komitmen untuk mempertahankan sumber daya dalam rangka mendukung efektifitas program (Frieden, 2013).

Sejalan dengan penelitian Lubis tahun 2012 yang berjudul "Analysis Of The Implementation Of Children Undernutrition Improvement Program In Working Area Medan Labuhan Health Center Medan City At 2008" Hasil penimbangan masih rendah, capaian balita yang naik berat badannya (N/D) dari bulan Januari sampai Desember 2008 sebesar 34,58 sampai 69,35 persen dari target cakupan 80 persen. Distribusi MP-ASI tidak sesuai dengan pedoman, selain diberikan kepada bayi kurang gizi dari keluarga miskin, MP-ASI diberikan kepada semua balita yang datang ke Posyandu. Demikian pula cakupan ASI Eksklusif, bulan Januari-November 2008 hanya 1,45 sampai 6,36 persen dari target 80 persen. Hal ini menunjukkan masih rendahnya tingkat pengetahuan dan kesadaran masyarakat tentang pola asuh anak dan kurangnya partisipasi kader dalam kegiatan posyandu. Implementasi program penanggulangan gizi buruk ditinjau dari segi input, proses dan output di Puskesmas Medan Labuhan masih kurang baik.

Penelitian ini sejalan dengan penelitian Ridwan tahun 2013 bahwa cakupan suplementasi vitamin A pada anak sebesar 70,5\% dan bervariasi antar provinsi, lebih tinggi di perkotaan $(75,3 \%)$ dari pada di perdesaan $(65,6 \%)$.
Sebagian besar cakupan suplementasi vitamin A dicapai melalui Posyandu.

Berdasarkan hasil penelitian yang dilakukan Fauziah diketahui bahwa hanya cakupan kelurahan yang mencapai UCI yang memenuhi target SPM kesehatan tahun 2010, sedangkan untuk cakupan kunjungan bumil K-4, ibu hamil risti yang dirujuk, balita yang datang dan ditimbang, serta bayi mendapat ASI eksklusif di bawah target SPM kesehatan dan dalam pelaksanaannya terdapat faktor penghambat dan juga faktor pendukung.

Menurut hasil penelitian Maritalia bahwa fungsi pengorganisasian dan penggerakan belum maksimal dilakukan, masih terdapat faktor penghambat pelaksanaan program SDIDTK di Puskesmas seperti masih ada penanggung jawab program SDIDTK yang belum pernah mendapatkan pelatihan SDIDTK, belum tersosialisasinya program SDIDTK di Puskesmas dan jaringannya dengan baik dan benar, fasilitas pendukung pelaksanaan program SDIDTK di puskesmas masih belum memadai dan kurangnya dukungan dari kepala puskesmas untuk pelaksanaan program ini di puskesmas sehingga tujuan akhir program belum tercapai seperti yang diharapkan.

Menurut asumsi peneliti, agar hasil cakupan program continuum of care pada pelayanan kesehatan bayi dan balita ini tercapai sebaiknya ada kerja sama antara dinas kesehatan, dinas pendidikan dan keluarga, seperti berkoordinasi dalam membentuk mata rantai kerja yang saling membutuhkan dan melengkapi sehingga hasil dari program yang direncanakan dapat lebih maksimal. Walaupun banyak faktor yang mempengaruhi seperti faktor lingkungan, faktor sosial ekonomi dan faktor perilaku baik itu masyarakat ataupun dari petugasnya. Untuk program continuum of care pada 
pelayanan kesehatan bayi dan balita sebaiknya diiringi juga dengan PHBS agar program ini berjalan sehingga dapat menurunkan angka kematian dan angka kesakitan anak.

\section{SIMPULAN}

Berdasarkan hasil wawancara mendalam dengan partisipan, dapat disimpulkan sebagai berikut :

Kebijakan program continuum of care ini pada prinsipnya mengacu pada visi dan misi Walikota Kota Bukittinggi. Ketersediaan tenaga pelaksana program ini dari segi jumlah masih kekurangan, rata-rata tenaga pelaksana tersebut berpendidikan D III dan S 1 atau D 4 Kebidanan, walaupun masih ada dengan pendidikan D I tetapi dalam masa pendidikan. Dana untuk program continuum of careini sudah mencukupi dan tidak ada kendala. Berdasarkan Permenkes 75 tahun 2014 mengenai sarana dan prasarana, diharapkan semua puskesmas untuk dapat lebih melengkapi sarana dan prasarana yang dibutuhkan untuk mendukung pelaksanaan program continuum of careini

Untuk pelaksanaan dan pengawasan program continuum of careini sudah berjalan dengan baik, walaupun ada beberapa kendala dalam pelaksanaannya, seperti masyarakatnya yang tidak mau berkunjung ke posyandu, petugas yang pekerjaannya rangkap maupun target atau sasaran yang ditetapkan terlalu tinggi atau ketidaksesuaian data antara data yang sebenarnya dengan data capil. Adanya pengawasan dilaksanakan oleh pimpinan puskesmas atau oleh dinas kesehatan dan evaluasinya dengan membuat laporan bulanan.

Pencapaian program continuum of care pada pelayanan kesehatan bayi dan balita di puskesmas Kota Bukittinggi belum mencapai SPM, itu dikarenakan masih adanya kematian neonatal seperti IUFD, kematian bayi dengan BBLR dan asfiksia, dan kematian balita dengan penyakit penyerta, DDTK pada balita tidak tercapai. Kematian neonatus dan bayi dapat dicegah dengan melihat riyawat penyakit ibu disaat hamil dengan meningkatkan pelayanan ANC yang lebih berkualitas. Ini dipengaruhi oleh sosial budaya masyarakat seperti tidak ada kunjungan ANC, tidak datang pada saat posyandu, terlalu sibuk karna bekerja, dan lain sebagainya. Kemudian juga dipengaruhi oleh petugas yang pekerjaannya rangkap dan angka yang ditargetkan terlalu tinggi sehingga tidak ditemukan sasarannya. Agar program continuum of care pada anak ini bisa berjalan khususnya pada DDTK, sebaiknya ada kerja sama antara Dinas Kesehatan, Dinas Pendidikan, dan Tim Penggerak PKK serta orang tua murid.

\section{UCAPAN TERIMAKASIH}

Penulis mengucapkan terimakasih kepada Dinas Kesehatan Kota Bukittinggi beserta Pimpinan Puskesmas diWilayah Kerja Dinas Kesehatan Kota Bukittinggi yangtelah memberikan kesempatan untukmelakukan penelitian.Penulis juga mengucapkan terima kasih kepadaPetugas Kesehatan setempat yang telahmembantu peneliti dalam melakukanpenelitian.

\section{DAFTAR PUSTAKA}

AAFP. Continuity of Care, Definition of. Journals Am Acad Fam Physicians [Internet]. 2015;

Aridewi A, et al. Analisis Pemanfaatan Bantuan Operasional Kesehatan dalam Upaya Peningkatan Kesehatan Ibu dan Anak di Puskesmas Wilayah Kerja Dinas Kesehatan Kabupaten Kudus. Manaj Kesehat Indones. 2013;1.

Abdul Rahim HF, Wick L, Halileh S, Hassan-Bitar S, Chekir H, Watt $\mathrm{G}$, et al. Health in the Occupied Palestinian Territory 2 Maternal 
and child health in the occupied Palestinian territory. Lancet. 2009;373.

Bachtiar dan Suarli. Manajemen Keperawatan dengan Pendekatan Praktis. Jakarta: Erlangga; 2010.

Brown BJ, Oladokun RE, Osinusi K. Situation analysis of the existing infant feeding pattern at the commencement of the prevention of mother to child transmission (PMTCT) of HIV programme in Ibadan. Niger J Clin Pract. 2009;

Cyril M Engmann Abraham Hodgson Raymond Aborigo Philip L. Adongo Cheryl A. Addressing the continuum of maternal and newborn care in Ghana: implications for policy and practice. Health Policy Plan [Internet]. 2016; Volume 31,:Pages 1355-1363.

Darmstadt GL, Kinney M V., Chopra M, Cousens S, Kak L, Paul VK, et al. Who has been caring for the baby? The Lancet. 2014.

Dinkes. Profil kesehatan Indonesia 2015. Indonesia; 2015.

Dinkes. Profil kesehatan kota Bukittinggi. 2016;

Dinkes. Profil kesehatan kota Bukittinggi. 2015;

Efendi dan Kurniati. Kajian SDM Kesehatan di Indonesia. Jkt: Salemba Medika; 2012 p.

Frieden. Six Components Necessary for Effective Public Health Program Implementation. Am J Public Health. 2014; Vol. 104,

Halwatiah. Implementasi Kebijakan Pelayanan Kesehatan Ibu Dan Anak Di Kabupaten Takalar Provinsi Sulawesi Selatan. Stikes Anging Mamiri Makasar, SulSel.

Hidayat W, Studi Tentang Pelaksanaan Pelayanan Kesehatan Di Puskesmas Long Ikis Kecamatan Long Ikis Kabupaten Paser. Ilmu Pemerintah. 2015;3(4):1637-51.
Iswarno dkk. Analysis For Policy Implementation: Stakeholder Analysis Of Maternal, Neonatal And Child Health Program Policy In Kepahiang Rege. J Kebijak Kesehat Indones Juni. 2013;02, No 02:77-85.

Joseph de Graft-Johnson, Kate Kerber, Anne Tinker, Susan Otchere, Indira Narayanan, Rumishael Shoo, Doyin Oluwole JLI, Mothers. The maternal, newborn, and child health continuum of care Joseph. Oppor Africa's Newborns.

Kate J Kerber, Joseph E de GraftJohnson, Zulfi qar A Bhutta, Pius Okong, Ann Starrs JEL, Lancet. Continuum of care for maternal, newborn, and child health: from slogan to service delivery. Lancet. 2007;370.

Kc A, Bhandari A, Yv P, Np K, Sr U, Thapa K, et al. State of Maternal, Newborn and Child Health Programmes in Nepal: What May a Continuum of Care Model Mean for More Effective and Efficient Service Delivery? JNHRC. 2011;9(2).

Kikuchi K, et al. Effective linkages of continuum of care for improving neonatal, perinatal, and maternal mortality: A systematic review and meta-analysis. PLoS One. 2015;

Kinney M V, Kerber KJ, Black RE, Cohen B, Nkrumah F, Coovadia $\mathrm{H}$, et al. Sub-Saharan Africa's Mothers, Newborns, and Children: Where and Why Do They Die? PLoS Med. 2010;7(6).

Kumar V, Mohanty S, Kumar A, Misra RP, Santosham M, Awasthi S, et al. Effect of community-based behaviour change management on neonatal mortality in Shivgarh, Uttar Pradesh, India: a cluster-randomised controlled 
trial. Lancet. 2008;372.

Kurniati, A dan Efendi F. Kajian SDM Kesehatan di Indonesia. Jakarta: Salemba Medika; 2012.

L Paruntu BR, M Rattu AJ, Tilaar CR, Kesehatan Kabupaten Minahasa D, Ilmu Kesehatan Masyarakat Universitas Sam Ratulangi Manado F, Pascasarjana Universitas Sam Ratulangi Manado P, et al. Human Resource Requirements Planning in Health Center Minahasa District. JIKMU. 2015;5, No. 1.

Liu L, Oza S, Hogan D, Perin J, Rudan I, Lawn JE, et al. Global, regional, and national causes of child mortality in 2000-13, with projections to inform post-2015 priorities: An updated systematic analysis. Lancet. 2015;

Lubis Z, Tampubolon E, Jumirah D. Analisis Implementasi Program Penanggulangan Gizi Buruk Pada Anak Balita Di Wilayah Kerja Puskesmas Medan Labuhan, Kota Medan Tahun 2008 (Analysis Of The Implementation Of Children Undernutrition Improvement Program In Working Area Medan Labuhan Health Ce. Penel Gizi Makan. 2012;35(1):70-7.

Maritalia D. Analisis Pelaksanaan Program SDIDTK Balita dan Anak Pra Sekolah di Puskesmas Kota Semarang. Progr Pascasarj Univ Diponegoro Semarang. 2009;

Marliana dan Reni. Continuum of Care to Improve Maternal and Neonatal Health in The District Subang. Int Conf Midwives. 2016;

Marniyati L, Saleh I, Soebyakto BB. Pelayanan Antenatal Berkualitas dalam Meningkatkan Deteksi Resti pada bumil oleh Tenaga Kesehatan di Puskesmas Sako,
Sosial, Sei Baung dan Sei Selincah di Kota Palembang. Univ Sriwijaya, Palembang. 2016;3(2016):355-62.

Maryanti dkk. Buku Ajar Neonatus, Bayi dan Balita. Jakarta: TIM; 2011.

Maryunani A. Asuhan Bayi dengan Berat Badan Lahir Rendah (BBLR). Jakarta: TIM; 2013.

Memon ZA, Khan GN, Soofi SB, Baig IY, Bhutta ZA. Impact of a community-based perinatal and newborn preventive care package on perinatal and neonatal mortality in a remote mountainous district in Northern Pakistan. BMC Pregnancy Childbirth. 2015;

Menkes. Indikator Pembangunan Berkelanjutan. 2016;

Menkes. Peraturan Menteri Kesehatan Nomor 25 Tahun 2014 tentang upaya kesehatan anak. 2014;

Menkes. Peraturan Menteri Kesehatan Republik Indonesia Nomor 75 Tahun 2014 tentang Puskesmas. 2014;

Menkes. Peraturan Menteri Kesehatan Nomor 741 Tahun 2008 tentang standar pelayanan minimal bidang kesehatan dikabupaten/ kota. 2008;

Menkes. Indikator Pembangunan Berkelanjutan 2016. Kementeri KesehatanJakarta. 2016;

Ridwan E. Cakupan Suplementasi Kapsul Vitamin A Dalam Hubungannya Dengan Karakteristik Rumah Tangga Dan Akses Pelayanan Kesehatan Pada Anak Balita Di Indonesia Analisis Data Riskesdas 2010.Bul Penelit Sist Kesehat. 2013;16, No. 1:1-9.

Saifuddin. Analisis Perencanaan dan Penganggaran Program Kesehatan Ibu dan Anak pada Puskesmas di Kota Banjar Tahun 
2007. Progr Pascasarj Univ Diponegoro Semarang. 2007;

Sari P. Ekuitas dalam Pemberian Pelayanan Kesehatan. Adm Kesehat Indones. 2013;1 No. 1.

Sibarani. Katadata News and Research. Meski Menurun, Angka Kematian Bayi di Indonesia Masih Tinggi. 2016.

Singh K, Story WT, Moran AC. Assessing the Continuum of Care Pathway for Maternal Health in South Asia and Sub-Saharan Africa. Matern Child Health J. 2016;

Subarsono. Analisis Kebijakan Publik, Konsep,Teori, dan Aplikasi. Yogyakarta: Pustaka Pelajar; 2008.

Subowo dkk. Monitoring Pelayanan Kesehatan Ibu Dan Anak Di Puskesmas Ngaliyan Semarang. Univ Diponegoro. 2012;

Tinker A, Ten Hoope-Bender P, Azfar S, Bustreo F, Bell R. A continuum of care to save newborn lives. The Lancet. 2005.

UNICEF. What Can Be Done: A Continuum of Maternal, Newborn And Child Health Care. 2008;

UNICEF. Levels and Trends in Child Mortality 2015. 2015;

Wang W, Hong R. Levels and determinants of continuum of care for maternal and newborn health in

Cambodia-evidence from a population-based survey. BMC Pregnancy Childbirth. 2015;

Yeji F, Shibanuma A, Oduro A, Debpuur C, Kikuchi K, OwusuAgei $\mathrm{S}$ et al. Continuum of Care in a Maternal, Newborn and Child Health Program in Ghana: Low Completion Rate and Multiple Obstacle Factors. PLoS One. 2015;

Yuyun M dan. Availability of Human
Resources for Health in Health Facilities in the Era of National Health Insurance in Eight Districts-Cities in Indonesia. Litbangkes. 2016;26, No. 4.

Yokbeth Kareth, Cahya Tri Purnami AS. Evaluasi Pelaksanaan Pencatatan dan Pelaporan Pelayanan Kia oleh Bidan di Puskesmas Kabupaten Nabire, Provinsi Papua (Studi Kasus di Puskesmas Distrik Nabire). Manaj Kesehat Indones. 2015;03, No. 01.

Zahtamal, Tuti Restuastuti FC. Analisis Faktor Determinan Permasalahan Pelayanan Kesehatan Ibu dan Anak Determinant. Kesehat Masy Nas. 2011;(6, No. 1).

Zohra S Lassi, Rehana A Salam, Jai K Das 1 and Zulfiqar A Bhutta. Essential interventions for maternal, newborn and child health: background and methodology. Reprod Heal Biomed Cent. 2014;

Zulfiqar A Bhutta, Mickey Chopra, Henrik Axelson, Peter Berman, Ties Boerma, Jennifer Bryce, Flavia Bustreo, Eleonora Cavagnero, Giorgio Cometto, Bernadette Daelmans, Andres de Francisco, Helga Fogstad, Neeru Gupta, Laura Laski, Joy Lawn, Blerta Maliqi, E TW. Countdown to 2015 decade report (2000-10): taking stock of maternal, newborn, and child survival. 